\title{
Distribution of Thiabendazole-Resistant Colletotrichum musae Isolates from Guadeloupe Banana Plantations
}

L. de Lapeyre de Bellaire, CIRAD-FLHOR, Unité de recherche biologie et contrôle des parasites et ravageurs, station de Neufchâteau, 97130 Capesterre-belle-eau, Guadeloupe, F.W.I.; C. Dubois, CIRAD-FLHOR, Unité de recherche biométrie et informatique, 2477 avenue de Montferrand, B.P. 5035, 34032 Montpellier Cédex 1, France

\begin{abstract}
de Lapeyre de Bellaire, L., and Dubois, C. 1997. Distribution of thiabendazole-resistant Colletotrichum musae isolates from Guadeloupe banana plantations. Plant Dis. 81:1378-1383.

In Guadeloupe, anthracnose of bananas, caused by Colletotrichum musae, is commonly controlled by postharvest thiabendazole treatments. A survey was conducted in 45 banana packing stations of Guadeloupe to determine the proportion of isolates that were resistant to thiabendazole. Isolates resistant to thiabendazole concentrations of $1 \mu \mathrm{g} / \mathrm{ml}$ (R1), $5 \mu \mathrm{g} / \mathrm{ml}$ (R5), and 50 $\mu \mathrm{g} / \mathrm{ml}$ (R50) were detected. Most of the resistant isolates were R1 or R5, and of 1,350 isolates, the proportion of resistant isolates (R1 + R5 + R50) was $23 \%$, ranging from 0 to $70 \%$ depending on the location. The presence of resistant isolates was correlated with the exclusive use of benomyl as foliar aerial sprays from 1972 to 1982 to control Sigatoka disease. Isolates resistant to concentrations of 1 and $5 \mu \mathrm{g} / \mathrm{ml}$ were as pathogenic as the susceptible isolates and were not controlled satisfactorily by postharvest thiabendazole treatments. Alternative control measures and the importance of resistance in terms of anthracnose control in Guadeloupe are discussed.
\end{abstract}

Additional keywords: cross-resistance, postharvest disease, postharvest treatments

Anthracnose, caused by Colletotrichum musae (Berk. \& M.A. Curtis) Arx, is the main postharvest disease affecting bananas from the French West Indies, causing brown fruit rot during ripening. In Guadeloupe, the disease is particularly severe from September to February in the lowland banana plantations where fruit growth is very fast, and anthracnose is considered to be the main factor affecting fruit marketability.

The pathogen is easily isolated from rotten fruits $(12,14,17,22)$. Conidia germinate rapidly on fruits and form "quiescent" infections through appressoria that remain inactive until fruit ripening $(4,19)$. During ripening, appressoria form penetration hyphae that colonize the underlying tissues and lead to anthracnose lesions. Fruit injuries promote rot development (16) and increase fruit losses.

Anthracnose is controlled through postharvest fungicide treatments with thiabendazole $(10,21)$. Thiabendazole-resistant isolates of $C$. musae have been recently isolated on bananas exported from Martinique (14) and from the Windward Islands (15). Nevertheless, the status of resistance

Corresponding author: L. de Lapeyre de Bellaire E-mail: lapeyre@cirad.fr

Accepted for publication 1 August 1997.

Publication no. D-1997-0929-02R

(C) 1997 The American Phytopathological Society to thiabendazole was unknown in Guadeloupe. The objective of this study was to evaluate thiabendazole resistance in different geographic and climatic areas of this island in order to determine whether the detection of resistant isolates in vitro could be related to anthracnose control failures (20). Thus, an outbreak of resistant isolates might explain severe anthracnose in bananas exported from some areas of Guadeloupe, especially in the lowland plantations where anthracnose is regularly severe.

Slabaugh and Grove (23) suggested that aerial sprays of benomyl for Sigatoka disease control lead to a build-up of benzimidazole-resistant isolates of crown rot pathogens, among which is $C$. musae. In Guadeloupe, benomyl was used exclusively as aerial foliar sprays from 1972 to 1982 to control the disease, which led to resistance in Pseudocercospora musae (Zimm.) Deighton populations $(3,7)$. After 1982, benomyl use was reduced, and this fungicide was alternated with sterol inhibitors. Because there is positive cross-resistance between benomyl and thiabendazole, another purpose of this work was to evaluate whether resistance to thiabendazole is related to benomyl aerial foliar sprays for Sigatoka control.

\section{MATERIALS AND METHODS}

Sampling. Samples were collected in 1992 from 45 banana plantations corresponding to different Sigatoka control spraying zones where climatic conditions differed substan- tially (Table 1). At each location, 50 untreated fruits were arbitrarily sampled in the packinghouse station before the postharvest treatment with thiabendazole to evaluate the proportion of resistant isolates in the field. Fruits were treated with ethephon (Ethrel) to accelerate their maturation, and stored in boxes at $24^{\circ} \mathrm{C}$ in the laboratory for 1 week. Typical orange acervuli developed on ripe fruits, and 30 acervuli, 1 from each of 30 different fruits, were spread on $30 \%$ agar for single-spore isolation. Single-spore isolates were transferred to potato dextrose agar (PDA) and incubated for 3 days. For each location, 30 singlespore isolates were collected; a total of 1,350 isolates were collected for the study.

Evaluation of in vitro resistance to thiabendazole. Sensitivity to thiabendazole was evaluated by an inhibition test of mycelial growth. Four 4- $\mathrm{mm}^{2}$ plugs removed from the edges of 3-day-old colonies were each transferred to $20 \%$ agar amended with thiabendazole concentrations of 1,5 , and $50 \mu \mathrm{g} / \mathrm{ml}$, and $20 \%$ agar without thiabendazole was used as a control. Stock solutions of thiabendazole were prepared the same day from Mertect $20 \mathrm{~S}$ (220 g a.i./ liter), MSD AGVET. Colony diameter was measured 3 days after incubation at room temperature $\left(24^{\circ} \mathrm{C}\right)$ for each concentration and compared to that in the control media. Isolates were classified into four groups: $\mathrm{S}$, susceptible (no growth with a thiabendazole concentration of $1 \mu \mathrm{g} / \mathrm{ml}$ ); R1, isolates resistant to a thiabendazole concentration of $1 \mu \mathrm{g} / \mathrm{ml}$ (but no growth at $5 \mu \mathrm{g} / \mathrm{ml}$ ); R5, isolates resistant to a thiabendazole concentration of $5 \mu \mathrm{g} / \mathrm{ml}$ (but no growth at 50 $\mu \mathrm{g} / \mathrm{ml}$ ); and R50, isolates resistant to a thiabendazole concentration of $50 \mu \mathrm{g} / \mathrm{ml}$ (growth on $50 \mu \mathrm{g} / \mathrm{ml}$ ). Some isolates grew only slightly ( 2 to $3 \mathrm{~mm}$ ) on thiabendazoleamended media and were not considered resistant. Resistant isolates always had growth superior to $50 \%$ of the control.

Pathogenicity tests and in vivo resistance to thiabendazole. Five isolates of the different categories (, , R1, and R5) were used for pathogenicity tests and evaluation of thiabendazole control. Fruits for inoculations came from the second cluster (from the top) of fruits coming from bunches collected in the same banana plot at the CIRAD-FLHOR experimental station of 
Neufchâteau, Guadeloupe. Ten replicates from ten bunches were used, and fruits were grouped in batches for use as control or for thiabendazole treatment. All isolates were cultured on PDA for 10 days, conidia were removed by flooding the plates with sterile distilled water, and spore concentrations were adjusted to $10^{6}$ conidia per $\mathrm{ml}$. Fruits were surface-sterilized with $50 \%$ ethanol before wounding. A cork borer was used to make an annular wound, $10 \mathrm{~mm}$ in diameter, on each fruit. After wiping the exuded latex from the wound, the cork borer, previously dipped in the spore solution, was applied to the wound. Thiabendazole treatment was carried out by dipping the fruits in a $500 \mu \mathrm{g} / \mathrm{ml}$ bath for $2 \mathrm{~min}$. Fruit were kept in room conditions before the thiabendazole treatment, which was applied $4 \mathrm{~h}$ after inoculation to enable germination of conidia and to prevent them from being washed from the fruit surface. Control fruits were dipped in water for $2 \mathrm{~min}$. After treatment, fruits from different batches were placed in commercial boxes and stored at $21^{\circ} \mathrm{C}$. The diameter of the rot was recorded 13 days after inoculation when the fruits were ripe; the $10 \mathrm{~mm}$ diameter of the wound was subtracted. Data were analyzed by analysis of variance, and the Student-NewmanKeuls comparison test was used to compare differences of treatment means.

Statistical analysis of the resistance distribution. The proportion of resistant isolates $(\% \mathrm{RT}=\% \mathrm{R} 1+\% \mathrm{R} 5+\% \mathrm{R} 50)$ was related with five putative explanatory factors (Table 1), as follows:

(i) The annual sprays for Sigatoka control (ASC), which is the mean number of annual aerial fungicide sprays for Sigatoka
Table 2. Lesion diameter (in millimeters) of wounded bananas inoculated with sensitive or resistant isolates ${ }^{y}$ of Colletotrichum musae

\begin{tabular}{lccc}
\hline Treatment & $\mathbf{S}$ & \multicolumn{1}{c}{ R1 } & R5 \\
\hline Control & $31.98 \mathrm{a}^{\mathrm{z}}$ & $32.88 \mathrm{a}$ & $35.4 \mathrm{a}$ \\
Mertect 20S & $1.14 \mathrm{~b}$ & $20.6 \mathrm{~b}$ & $29.5 \mathrm{a}$ \\
\hline
\end{tabular}

y Means of 5 isolates inoculated on 10 fruits each. $\mathrm{S}=$ sensitive isolates, $\mathrm{R} 1=$ isolates resistant to a thiabendazole concentration of $1 \mu \mathrm{g} / \mathrm{ml}$, and R5 = isolates resistant to a thiabendazole concentration of $5 \mu \mathrm{g} / \mathrm{ml}$. Bananas were dipped for $2 \mathrm{~min}$ in a thiabendazole (Mertect 20S) concentration of $500 \mu \mathrm{g} / \mathrm{ml}$ or in water (control) and incubated 13 days at $21^{\circ} \mathrm{C}$.

${ }^{\mathrm{z}}$ Numbers within columns followed by the same letter are not different according to the Student-Newman-Keuls comparison test $(P$ $<0.05)$.

Table 1. Description of banana plantations in Guadeloupe sampled for thiabendazole-resistant isolates of Colletotrichum musae

\begin{tabular}{|c|c|c|c|c|c|c|c|c|c|c|}
\hline Plantation & Name & $\% \mathbf{R 1}^{\mathrm{y}}$ & $\% \mathrm{R5}$ & $\% \mathrm{R50}$ & $\%$ RT & $\mathbf{A S C}^{\mathbf{z}}$ & NBT & Alt & Piche & Wind \\
\hline 1 & Bonne mère & 16 & 10 & 0 & $26(2)$ & 8.1 & 14 & 35 & 25.2 & 15 \\
\hline 2 & Prise d'eau & 23 & 0 & 0 & $23(3)$ & 6.1 & 22 & 80 & 20.3 & 15 \\
\hline 3 & Féneteau & 30 & 0 & 0 & $30(3)$ & 6.7 & 16 & 150 & 19.6 & 15 \\
\hline 4 & Montebello & 30 & 7 & 0 & $37(2)$ & 8 & 10 & 180 & 19.6 & 15 \\
\hline 5 & La rose & 4 & 4 & 0 & $8(5)$ & 3.4 & 11 & 10 & 27.2 & 20 \\
\hline 6 & Rivière morin & 20 & 47 & 3 & $70(1)$ & 8.7 & 25 & 160 & 19.6 & 15 \\
\hline 7 & Moreau & 20 & 10 & 0 & $30(3)$ & 7.1 & 11 & 170 & 19.6 & 15 \\
\hline 8 & Christophe & 10 & 30 & 3 & $43(3)$ & 5.1 & 23 & 110 & 27.2 & 15 \\
\hline 9 & Richebois & 10 & 3 & 0 & $13(4)$ & 7.4 & 12 & 190 & 17.7 & 15 \\
\hline 10 & Changy & 3 & 3 & 3 & $9(5)$ & 2.6 & 11 & 30 & 22.1 & 15 \\
\hline 11 & Besnard bisson & 19 & 6 & 3 & $28(3)$ & 4.4 & 19 & 100 & 22.1 & 15 \\
\hline 12 & Bois rouge & 6 & 26 & 0 & $32(2)$ & 7.6 & 10 & 380 & 17.7 & 15 \\
\hline 13 & Digue & 20 & 13 & 0 & $33(3)$ & 5.4 & 10 & 230 & 22.1 & 15 \\
\hline 14 & Cambrefort & 7 & 13 & 0 & $20(3)$ & 4.9 & 31 & 110 & 22.1 & 15 \\
\hline 15 & Lotissement féfé & 27 & 23 & 0 & $50(2)$ & 8.1 & 25 & 380 & 17.7 & 15 \\
\hline 16 & Sarde basse & 27 & 3 & 0 & $30(3)$ & 3.7 & 16 & 45 & 27.2 & 20 \\
\hline 17 & Grand rivière & 0 & 0 & 0 & $0(5)$ & 1.3 & 11 & 45 & 34.2 & 20 \\
\hline 18 & Bois brulé & 0 & 10 & 0 & $10(3)$ & 5 & 14 & 80 & 28.5 & 15 \\
\hline 19 & Concession & 13 & 17 & 0 & $30(4)$ & 7.3 & 12 & 320 & 17 & 15 \\
\hline 20 & Manceau & 7 & 21 & 4 & $32(3)$ & 5.6 & 12 & 200 & 21.3 & 15 \\
\hline 21 & Blondinière & 26 & 3 & 0 & $29(3)$ & 4.7 & 22 & 100 & 21.3 & 15 \\
\hline 22 & Dumanoir & 0 & 17 & 0 & $17(3)$ & 5.9 & 19 & 210 & 21.3 & 15 \\
\hline 23 & Bois debout & 3 & 3 & 3 & $9(5)$ & 3.4 & 10 & 110 & 28.8 & 20 \\
\hline 24 & Montbelley & 10 & 0 & 20 & $30(4)$ & 5.9 & 12 & 240 & 17.1 & 15 \\
\hline 25 & Moulin à eau & 7 & 3 & 3 & $13(5)$ & 2.9 & 11 & 45 & 34.2 & 20 \\
\hline 26 & Mineurs & 0 & 0 & 0 & $0(5)$ & 1 & 4 & 50 & 43.2 & 20 \\
\hline 27 & St. Sauveur & 3 & 0 & 0 & $3(5)$ & 2.9 & 12 & 50 & 28.8 & 20 \\
\hline 28 & Grand étang & 0 & 14 & 0 & $14(2)$ & 8 & 14 & 300 & 17.1 & 25 \\
\hline 29 & Habituée & 0 & 0 & 3 & $3(4)$ & 6.7 & 22 & 200 & 17.1 & 25 \\
\hline 30 & Tabaco & 0 & 3 & 7 & $10(4)$ & 6.4 & 37 & 270 & 17.1 & 30 \\
\hline 31 & Montplaisir & 0 & 0 & 0 & $0(4)$ & 3.9 & 30 & 100 & 14.5 & 30 \\
\hline 32 & Haute plaine & 0 & 16 & 3 & $19(4)$ & 5.9 & 37 & 220 & 11.6 & 30 \\
\hline 33 & Lafitte bunel & 23 & 19 & 0 & $42(1)$ & 7.9 & 34 & 420 & 11.6 & 35 \\
\hline 34 & Savane buissonet & 10 & 0 & 0 & $10(5)$ & 3.6 & 24 & 100 & 22.5 & 30 \\
\hline 35 & Gd fond Jaqmel & 39 & 3 & 0 & $42(4)$ & 6.1 & 41 & 450 & 11.6 & 40 \\
\hline 36 & Regrettée & 3 & 30 & 3 & $36(3)$ & 5 & 20 & 250 & 22.5 & 30 \\
\hline 37 & Dolé & 23 & 3 & 3 & $29(3)$ & 5.3 & 30 & 300 & 22.5 & 25 \\
\hline 38 & Gillardin & 10 & 0 & 0 & $10(4)$ & 4.9 & 31 & 210 & 14.5 & 25 \\
\hline 39 & Moscou & 19 & 35 & 0 & $54(1)$ & 8 & 48 & 650 & 9.5 & 45 \\
\hline 40 & St. Claude & 3 & 3 & 0 & $6(4)$ & 5.7 & 35 & 400 & 18.9 & 25 \\
\hline 41 & Matouba & 0 & 0 & 0 & $0(4)$ & 6.9 & 44 & 500 & 13.2 & 25 \\
\hline 42 & Haut Matouba & 3 & 0 & 0 & $3(4)$ & 6.1 & 38 & 650 & 13.2 & 35 \\
\hline 43 & Gd Marigot haut & 33 & 0 & 0 & $33(4)$ & 7 & 27 & 600 & 13.2 & 35 \\
\hline 44 & Gd Marigot bas & 17 & 13 & 0 & $30(3)$ & 3.9 & 15 & 470 & 26.4 & 20 \\
\hline 45 & Mont val & 0 & 30 & 0 & $30(3)$ & 5 & 31 & 550 & 21.1 & 35 \\
\hline
\end{tabular}

y $\% \mathrm{R} 1, \% \mathrm{R} 5$, and $\% \mathrm{R} 50$, are the proportions of isolates resistant to thiabendazole concentrations of 1,5 , or $50 \mu \mathrm{g} / \mathrm{ml}$, respectively; \%RT is the proportion of all resistant isolates (R1 + R5 + R50). Letters in parentheses correspond to the groups determined by regression-tree analysis.

${ }^{z}$ ASC is the mean number of annual aerial sprays for Sigatoka disease control from 1972 to 1982; NBT is the number of benomyl treatments from 1983 to 1991; Alt is the elevation of the plantation in meters; Piche is the Piche evaporation in millimeters; and Wind is the annual aeolian energy available at a height of $60 \mathrm{~m}\left(\times 100 \mathrm{Kwh} / \mathrm{m}^{2}\right)$. 
disease control carried out between 1972 and 1982 when benomyl was used exclusively. Data before 1972 were not available, and they were estimated from 1983 to 1991. Effectively, the number of annual sprays for Sigatoka control is quite constant for a single location; decisions to spray are based on a bioclimatic forecasting sys- tem. There is little between-year variation for the same area (2). So, ASC represents fungicide selection pressure with benzimidazole products from 1972 to 1982 when benomyl was used exclusively.

(ii) The number of benomyl treatments (NBT), which is the number of benomyl aerial sprays carried out from 1983 to 1991 , and represents the fungicide selection pressure with benzimidazole products exerted during this period. During this period, benomyl was alternated with propiconazole and tridemorph.

(iii) The altitude (Alt), which is the elevation of the plantation in meters. This parameter might be important because cli-

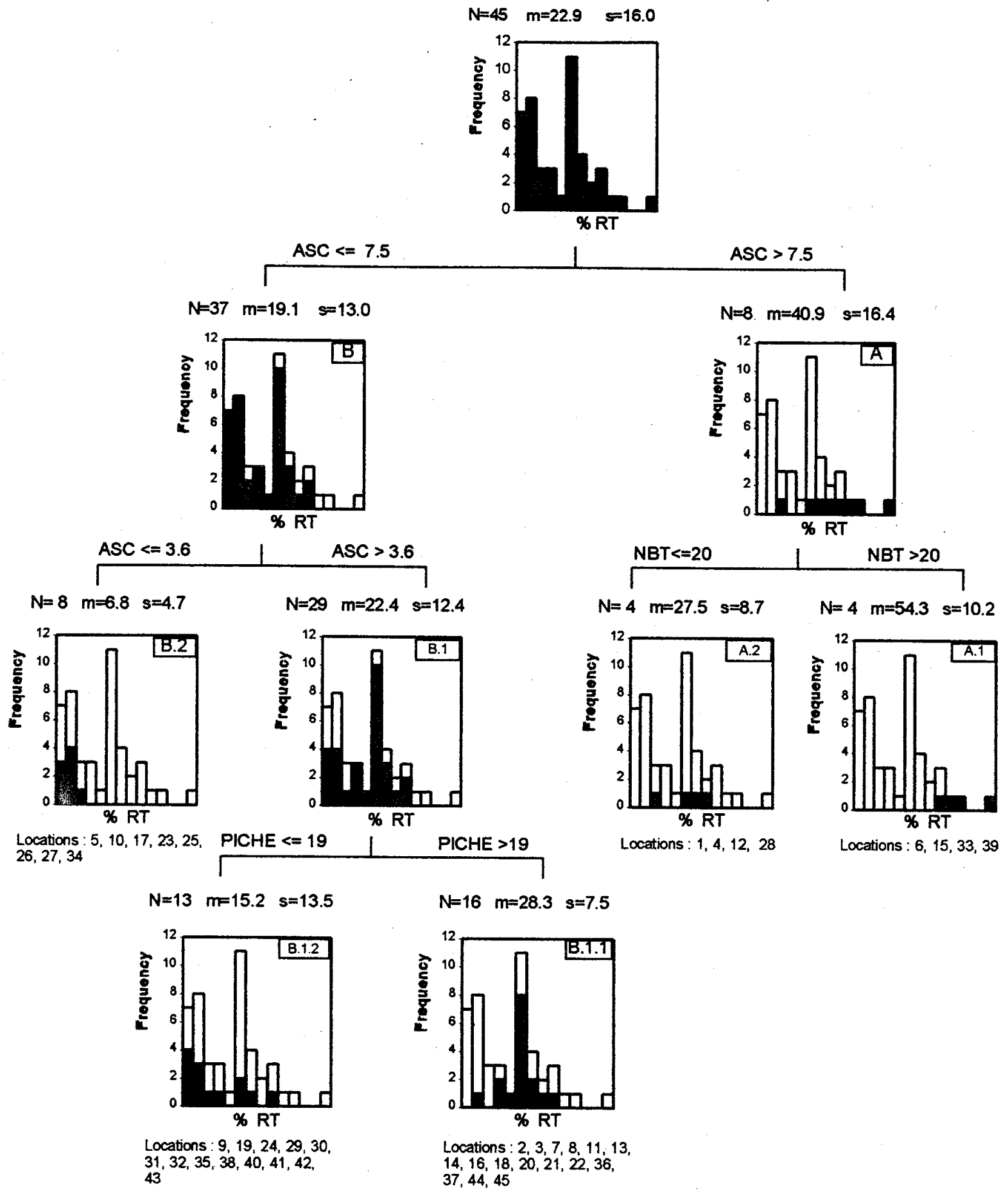

Fig. 1. Regression-tree analysis of the proportion of thiabendazole-resistant Colletotrichum musae isolates (\%RT [proportion of all resistant isolates]) based on: ASC, the average number of annual aerial sprays for Sigatoka control from 1972 to 1982; NBT, the number of benomyl treatments from 1983 to 1991 Alt, the elevation of the plantation in meters; Piche, the Piche evaporation in millimeters; and Wind, the annual aeolian energy available at a height of 60 meters $\left(\times 100 \mathrm{Kwh} / \mathrm{m}^{2}\right)$. \% RT is represented in 14 classes from 0 to $70 \%$, with an increment of $5 \%$ between each class. N is the size of the groups, $\mathrm{m}$ is the mean \%RT in the groups, and s is the standard deviation of \%RT within each group. The code number of the plantations is shown at the bottom of the class distribution of \% RT within each final group (solid portion of columns) compared to the whole sample (open portion of columns). Classification was stopped if $N<8$. Splits producing less than four objects in a subgroup were rejected, and the maximum number of levels in the tree was four. 
matic conditions are very dependent on the elevation. Moreover, in highland plantations aerial spraying of bananas is affected by air turbulence, and by a high flight altitude caused by the irregularity of topography and the presence of many natural obstacles.

(iv) Piche, which is the mean weekly Piche evaporation in millimeters. This climatic factor takes into account the temperature, humidity, and wind and is used to describe the hydric status of the leaf surface and to forecast aerial sprays for Sigatoka control (11).

(v) Wind, which is the annual aeolian energy available at a height of $60 \mathrm{~m}(\times 100$ $\mathrm{Kwh} / \mathrm{m}^{2}$ ) and represents the air turbulence (9) that might affect aerial spraying of bananas.

Data were processed by binary regression tree. This statistical method was first proposed by Morgan and Sonquist in 1963 (18) under the Automatic Interaction Detection (AID) algorithm. It investigates possible associations between a continuous dependent variable $(Y)$ and a set of categorical predictors $\left(X_{i}\right)$ by a stepwise procedure. Later, this method was to be adapted to the processing of any variable; more recently, Breiman et al. (1) added numerous theoretical developments to it and gave it a general configuration with the classification and regression trees (CART) methodology. The principle is, step after step, to split a set of objects into two subsets according to the values of a predictor $X_{i}$, such that objects within one subset are as homogenous as possible on the dependent variable $Y$, and as different as possible from the other subset objects. A categorical predictor with $q$ ordered categories allows $q-1$ different dichotomies of the set of objects. If $X_{i}$ is a continuous predictor, each value is considered as a category. A criterion is defined to evaluate the discriminative capacity of the dichotomy on the dependent variable $Y$. In the AID method, this criterion is the between-groups sum-of-squares. Each predictor is examined for its most adequate dichotomy of the initial population. The best one is chosen, and data are subdivided according to this predictor. At the next step, the same procedure is applied independently to each subgroup in turn and is followed through each branch until matching a predefined stopping rule. The gradual succession of these splits will generally be represented by a tree diagram. This method is a nonparametric alternative to multiple regression. Processing of each tree branch separately allows the detection of interactions even if complex, and when it would be difficult to express them with a linear model. The interest lies in the automatic detection, i.e., without previously defined specification. Moreover, the interpretation of results is more intuitive than with an algebraic model when it comes to describing the studied phenomenon: the way the studied population distribution varies along each branch stands out clearly. Last, the order in which relevant factors are sorted reveals their hierarchical importance. AID analysis was performed with SPAD.S package (SPAD.S version 2.5, Système Portable d'Analyse des Données. Segmentation. Centre International de Statistique et d'Informatique Appliquées. Saint-Mandé, France), using five continuous predictors. The minimum number of objects to divide a group was seven; splits giving less than four objects in a subgroup were rejected. The maximum number of levels in the tree was four.

\section{RESULTS}

Frequency of thiabendazole-resistant isolates in Guadeloupe banana plantations. Resistant (RT = R1 + R5 + R50) isolates ranged from 0 to $70 \%$ in the plantations (Table 1). Of the 1,350 C. musae isolates collected in the 45 plantations, $23 \%$ were resistant to thiabendazole, of which $11.7 \%$ belonged to the R1 group, $9.9 \%$ belonged to the R5 group, and $1.4 \%$ belonged to the R50 group.

Pathogenicity tests and in vivo resistance to thiabendazole. Resistant isolates of the R1 and R5 groups were as pathogenic as susceptible isolates (Table 2). No significant differences were observed for necrosis extension as compared on untreated bananas inoculated with isolates of the $\mathrm{S}$, R1, and R5 groups using a Student-Newman-Keuls comparison test.

Reduction of rot extension by Mertect 20S on bananas inoculated with sensitive isolates was excellent (Table 2). Resistant isolates of groups R1 and R5 were not controlled satisfactorily by the fungicide. R1 isolates were controlled only partially by the postharvest treatment, whereas R5 isolates were not significantly controlled (Table 2).

Distribution of thiabendazole resistance. The regression-tree analysis of the proportion of resistant isolates in the different banana plantations indicated that the main explanatory factor for this distribution was ASC. Plantations were first divided into two groups: A, with more than 7.5 sprays for Sigatoka disease control per year, and B, with 7.5 or fewer sprays per year (Fig. 1). Thus, the selection pressure exerted during the period of exclusive use of benomyl for Sigatoka control from 1972 to 1982 appears to be the main factor responsible for resistance to thiabendazole in C. musae populations.

Within plantations where the use of benomyl for Sigatoka disease control was more intensive from 1972 to 1982 (group A), the frequency of the use of benomyl during subsequent years had an affect on the levels of resistance to thiabendazole in $C$. musae populations. Group A split into two subgroups according to NBT, the number of benomyl sprays carried out from 1983 to 1991 (Fig. 1). Within subgroup A.1, 43\% of aerial sprays for control of Sigatoka disease contained benomyl during this period, and $54.3 \%$ resistant isolates were observed compared to subgroup A.2, within which the use of benomyl was less intensive (only $16 \%$ of aerial sprays for control of Sigatoka disease contained benomyl during this period), and fewer $(27.5 \%)$ resistant isolates were observed. No more division could be done on groups A.1 and A. 2 because the minimum number of objects to divide a group was seven.

Group B split again into two subgroups (B.1 and B.2) according to ASC, the selection pressure exerted during the period of exclusive use of benomyl for Sigatoka control from 1972 to 1982 , confirming the importance of this factor in explaining resistance to thiabendazole in $C$. musae populations. The proportion of resistant isolates was very low in subgroup B.2 (6.8\%), and less than 3.6 sprays per year are done in these plantations for Sigatoka disease control (Fig. 1). The analysis was stopped within subgroup B.2 because splits producing less than four objects in a subset were rejected.

B.1 split into two subgroups according to Piche evaporation. It is striking that

Table 3. Characteristics of the different groups (1 to 5) of the banana plantations with decreasing levels of resistance of Colletotrichum musae to thiabendazole, as determined by tree-structure analysis

\begin{tabular}{lccccc}
\hline & \multicolumn{5}{c}{ Mean value (min.-max.) } \\
\cline { 2 - 6 } Characteristic $^{\mathbf{z}}$ & $\mathbf{1}$ & $\mathbf{2}$ & $\mathbf{3}$ & $\mathbf{4}$ & $\mathbf{5}$ \\
\hline \%RT & $54.2(42-70)$ & $27.5(14-37)$ & $28.3(10-43)$ & $15.2(0-42)$ & $6.8(0-13)$ \\
ASC & $8.2(7.9-8.7)$ & $7.9(7.6-8.1)$ & $5.2(3.7-7.1)$ & $6.2(3.9-7.4)$ & $2.6(1-3.6)$ \\
NBT & $33(25-48)$ & $12(10-14)$ & $19.4(10-31)$ & $29.1(12-44)$ & $11.8(4-24)$ \\
Alt & $403(160-650)$ & $224(35-380)$ & $197(45-550)$ & $335(100-650)$ & $55(10-110)$ \\
Piche & $14.6(9.5-19.6)$ & $19.9(17.1-25.2)$ & $22.8(19.6-28.5)$ & $15.1(11.6-28.5)$ & $30.1(22.1-43.2)$ \\
Wind & $27.5(15-45)$ & $17.5(15-25)$ & $18.4(15-35)$ & $26.5(15-40)$ & $20.6(15-30)$ \\
\hline
\end{tabular}

\%RT is the proportion of all resistant isolates (R1 + R5 + R50); ASC is the mean number of annual aerial sprays for Sigatoka disease control from 1972 to 1982; NBT is the number of benomyl treatments from 1983 to 1991; Alt is the elevation of the plantation in meters; Piche is the Piche evaporation in millimeters; and Wind is the annual aeolian energy available at a height of $60 \mathrm{~m}\left(\times 100 \mathrm{Kwh} / \mathrm{m}^{2}\right)$. 
within group B.1.2, where Piche is lower, disease development is faster, and ASC is higher than in group B.1.1 (Table 3), the proportion of resistant isolates is lower (15.2\%) than in group B.1.1 (28.3\%).

All plantations, thus, were divided into five groups with decreasing levels of resistance: A.1 (54.3\%), A.2 (27.5\%), B.1.1 (28.3\%), B.1.2 (15.2\%), and B.2 (6.8\%). These five groups were renamed 1, 2, 3, 4, and 5, respectively. Their characteristics are summarized in Table 3, and they have been represented on a correlation chart between ASC and the proportion of resistant isolates (Fig. 2). The strikingly low proportion of resistance in some plantations of group 4, including 29, 30, 32, 40, 41, and 42 , is clearly shown in this chart.

\section{DISCUSSION}

The results of this study clearly show spread in banana plantations of Guadeloupe, as $23 \%$ of all isolates evaluated were resistant to a thiabendazole concentration of at least $1 \mu \mathrm{g} / \mathrm{ml}$, which is sufficient to result in control failure of postharvest treatments with this fungicide. Resistance to benzimidazole products in $C$. musae populations has also been reported in the Windward Islands for benomyl (13) and thiabendazole (15), in Central America (23), in the Philippines for benomyl (20), and in Martinique for thiabendazole (14). that resistance to thiabendazole is wide-

In the Windward Islands and Martinique, there are reports of similar levels of resistance through 50\% effective dose measurement, because three classes of resistant isolates were observed using similar limits (14, 15). In Martinique, of 29 isolates evaluated, $76 \%$ were resistant (14), and in the Windward Islands, only $17 \%$ of 54 isolates were resistant (15). Nevertheless, in these two studies carried out in Martinique and the Windward Islands, fruits were sampled in exported boxes after fungicide treatment with thiabendazole, and thus, the percentage of resistant isolates was over-estimated, because most susceptible isolates were controlled by the postharvest treatment and could not be isolated. In our study, samples were collected before thiabendazole treatment to evaluate the proportion of resistant isolates present in the field and to determine resistance distributions. However, in some areas fruits were treated with Mertect 20S before isolating, and the proportion of resistant isolates was very high (70 to $100 \%$; data not shown). The results from Guadeloupe and Martinique, therefore, revealed higher proportion of resistant isolates than those from the Windward Islands.

The regression-tree analysis of the distribution of resistance shows that the aerial sprays of benomyl for Sigatoka disease control are the primary factor associated with thiabendazole resistance in $C$. musae

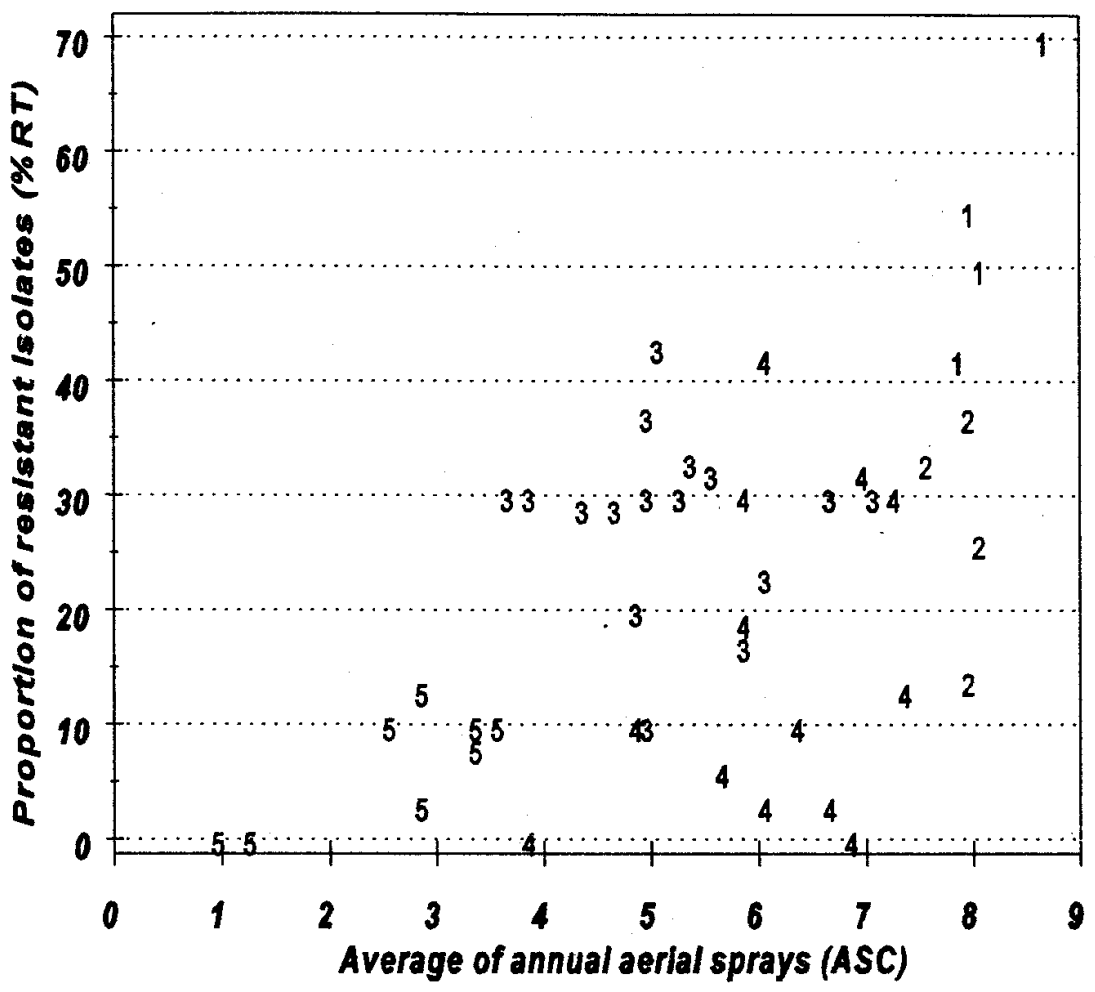

Fig. 2. Relationship between the proportion of thiabendazole-resistant Colletotrichum musae strains $(\% \mathrm{RT}=\% \mathrm{R} 1+\% \mathrm{R} 5+\% \mathrm{R} 50[\% \mathrm{R} 1, \% \mathrm{R} 5$, and \% 50 , are the proportions of isolates resistant to thiabendazole concentrations of 1,5 , or $50 \mu \mathrm{g} / \mathrm{ml}$, respectively; $\% \mathrm{RT}$ is the proportion of all resistant isolates]) and the mean number of annual aerial sprays for Sigatoka disease control (ASC) in the 45 banana plantations studied. Each plantation is represented by a number corresponding to one of the five groups determined by regression-tree analysis. populations. Although Slabaugh and Grove (23) suggested that sprays for Sigatoka disease control could account for resistance to benzimidazole products in crown rot pathogens, our research is the first to demonstrate the probable role played by this practice.

Despite relatively high ASC and NBT values, we observed a low percentage of resistant isolates in the group 4 plantations (especially 29, 30, 32, 40, 41, and 42), which could be explained by the difficulty of aerial spraying over these areas. The quantity of fungicide reaching targets can be altered by drift and interception of droplets by natural obstacles. In addition, pilots consider these areas dangerous to spray. This interpretation can be supported by the case of the Windward Islands, where bananas are commonly interplanted with coconuts, the topography is often irregular, and banana plantations are similar to those of group 4. Similarly, less fungicide could reach targets, which would account for the lower levels of resistance to thiabendazole observed in the Windward Islands. Moreover, no resistance of Pseudocercospora musae to benomyl has been reported in the Windward Islands (6), when at the same time it was widely distributed in Guadeloupe $(3,7)$, whereas the use of benomyl was more intensive in the Windward Islands (8 to 10 sprays per year).

Where resistant isolates are common, there is probably a failure of control of postharvest treatments, because these isolates are pathogenic and uncontrolled by thiabendazole treatments. Quimio (20) observed such a loss of efficacy of benomyl on resistant isolates in the Philippines. Nevertheless, anthracnose is regularly severe at the end of the year in lowland plantations of group 5, whereas the proportion of resistant isolates is very low in this area. Thiabendazole resistance, thus, cannot account for the higher anthracnose severity in this area of Guadeloupe banana plantations, and other factors might explain this situation. Recent results have pointed to the fact that fruit from these lowlands is more susceptible to mechanical damage, the preclimatic life is lower, and anthracnose development is faster on fruit artificially inoculated after harvest than on fruit coming from higher elevations (5). In addition, there was less postharvest control of anthracnose with thiabendazole on lowland fruit inoculated 15 days after bunch emergence and wounded at harvest, as compared to fruit coming from the highlands (L. de Lapeyre de Bellaire and M. Chillet, unpublished data).

In conclusion, postharvest control of anthracnose is faced with quite widespread thiabendazole resistance in C. musae populations in banana plantations of Guadeloupe. Imazalil, the only other fungicide approved for postharvest treatment of bananas, cannot be considered as a replacement because of its very low efficacy for 
anthracnose control (8). Some sterol biosynthesis inhibitor fungicides are very effective for postharvest control of banana anthracnose, but are not registered for use in the French West Indies. Moreover, these results emphasize the need for new control strategies involving lower pesticide use, which would be in line with consumer requirements.

\section{ACKNOWLEDGMENTS}

We thank V. Bon for technical assistance and X. Mourichon, CIRAD-FLHOR of Montpellier, for valuable discussions during the preparation of this manuscript.

\section{LITERATURE CITED}

1. Breiman, L., Friedman, J. H., Olshen, A., and Stone, C. J. 1984. Classification and regression trees. Belmont Books, Wadsworth, CA.

2. Bureau, E. 1984. Evolution de la lutte généralisée contre la cercosporiose du bananier en Guadeloupe. Fruits (Paris) 39:166-170.

3. Bureau, E., Ganry, J., Zapater, M. F., and Laville, E. 1982. Les cercosporioses du bananier et leurs traitements. Evolution des populations pathogènes. Distribution géographique et évolution des populations de Mycosphaerella musicola résistantes aux benzimidazoles dans les zones bananières de Guadeloupe. Fruits (Paris) 37:665-672.

4. Chakravarty, T. 1957. Anthracnose of banana (Gloeosporium musarum Cke. \& Massee) with special reference to latent infection in storage. Trans. Br. Mycol. Soc. 40:337-345.

5. Chillet, M., and de Lapeyre de Bellaire, L.
1995. Elaboration de la qualité des bananes au champ. Détermination de critères de mesure. Réunion annuelle CIRAD-FLHOR, Technologie et maîtrise de la qualité, Montpellier, France.

6. Cronshaw, D. K. 1984. Monitoring of Sigatoka disease (Mycosphaerella musicola Leach ex Mulder) in the Windward Islands for tolerance to fungicides. Fruits (Paris) 39:163-165.

7. de Lapeyre de Bellaire, L. 1990. Caractérisation de la sensibilité des souches de Pseudocercospora musae aux fongicides utilisés dans la lutte contre la cercosporiose jaune du bananier en Guadeloupe. Fruits (Paris) 45:209-212.

8. de Lapeyre de Bellaire, L., and Nolin, J. 1994. Amélioration du contrôle du chancre sur les bananes d'exportation et traitements post-récolte. Fruits (Paris) 49:179-185.

9. Delaunay, D. 1986. Geographical variation of wind characteristics in Martinique and Guadeloupe. Rapport Final, No. Contrat A.F.M.E. 5421001.

10. Frossard, P. 1969. Action du thiabendazole et du Benlate sur l'anthracnose des bananes et son champignon pathogène Colletotrichum musae. Fruits (Paris) 24:365-379.

11. Ganry, J., and Laville, E. 1983. Les cercosporioses du bananier et leurs traitements. Evolution des méthodes de traitement. I. Traitements fongicides. II. Avertissement. Fruits (Paris) 38:3-20.

12. Greene, G. L., and Goos, R. D. 1963. Fungi associated with crown rot of boxed bananas. Phytopathology 53:271-275.

13. Griffee, P. J. 1973. Resistance to benomyl and related fungicides in Colletotrichum musae. Trans. Br. Mycol. Soc. 60:433-439.

14. Hostachy, B., Vegh, I., Leroux, P., Jacquemot,
E., Foucher, S., and Pigou, R. 1990. Bananes de la Martinique. Incidence des problèmes fongiques sur la qualité. Phytoma 420:37-44.

15. Johanson, A., and Blasquez, B. 1992. Fungi associated with banana crown-rot on fieldpacked fruit from the Windward Islands and assessment of their sensitivity to the fungicides thiabendazole, prochloraz, and imazalil Crop Prot. 11:79-83.

16. Meredith, D. S. 1960. Studies on Gloeosporium musarum Cke. \& Massee causing storage rots of Jamaican bananas. I. Anthracnose and its chemical control. Ann. Appl. Biol. 48:279 290.

17. Mesturino, L., and Ragazzi, A. 1988. Microorganismi fungini associati ai frutti di Musa spp., presenti sul mercato italiano. Riv. Agric. Subtropic. Tropic. 82:503-515.

18. Morgan, J. A., and Sonquist, J. N. 1963. Problems in the analysis of survey data and a proposal. J. Am. Stat. Assoc. 58:415-434.

19. Muirhead, I. F., and Deverall, B. J. 1981. Role of appressoria in latent infection of banana fruits by Colletotrichum musae. Physiol. Plant Pathol. 19:77-84.

20. Quimio, T. H. 1976. Variability in Colletotrichum musae (Berk. et Curt.) V. Arx and its significance in chemical control. Phillip. Phytopathol. 12:40-50

21. Rippon, L. E., and Glennies-Holmes, M. 1973. Postharvest dipping of bananas. Agric. Gaz N.S.W. 84:229-231.

22. Shillingford, C. A. 1976. Occurrence of banana fruit-rot fungi in Jamaican boxing plants. Plant Dis. Rep. 60:788-793.

23. Slabaugh, W. R., and Grove, M. D. 1982. Postharvest diseases of bananas and their control. Plant Dis. 66:746-750. 